\section{Edycaçäa

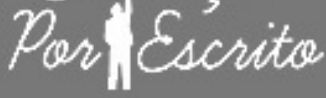

ARTIGO

\section{Editor}

Alexandre Anselmo Guilherme PUCRS, RS, Brasil

\section{Editor Assistente}

Cibele Cheron

PUCRS, RS, Brasi

\section{Editores Associados}

Bruno Antonio Picoli

Universidade Federal da Fronteira Sul, Chapecó, SC, Brasil

Pricila Kohls dos Santos Universidade Católica de Brasília, Brasília, DF, Brasil

Renato de Oliveira Brito

Universidade Católica de Brasilia, Brasilia, DF, Brasil

Elisa Ustarroz

PUCRS, Porto Alegre, RS, Brasil

\section{ISSN 2179-8435}

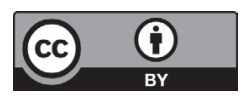

Este artigo está licenciado sob forma de uma licença Creative Commons Atribuição 4.0 Internacional, que permite uso irrestrito, distribuiçăa e reproduçãa em qualquer meio, descasa
seja corretamente citada. hitp://creativecommons.org/licenses/by/4.0/deed.pt_BP

\title{
Astronomia e Matemática: uma proposta interdisciplinar para o Ensino Fundamental II
}

\author{
Astronomy and Mathematics: an interdisciplinary proposal for Elementary School
}

\author{
Amanda Cristina Tedesco Piovezan ${ }^{1}{ }^{1}$ \\ Leandro Daros Gama ${ }^{2}{ }^{2}$ \\ Universidade de São Paulo, São Paulo, SP, Brasil. \\ ${ }^{2}$ Instituto Federal de São Paulo, São Paulo, SP, Brasil.
}

\section{RESUMO}

Discutem-se, inicialmente, alguns aspectos vantajosos em construir um diálogo entre a realidade que excede os muro da escola e o conhecimento científico que esta promove, incluindo-se, para isto, a prática da interdisciplinaridade como representação mais completa do mundo. Com base nessa discussão e no questionamento da representação, no senso comum, da matemática e das ciências naturais como inacessíveis a grande parte do público, propomos o exemplo de uma sequência didática na qual a participação de equipes de estudantes são convidados a resolver problemas e a responder questões interdisciplinares, envolvendo astronomia e matemática, no intuito de, ao se explorar múltiplas habilidades, cada estudante tenha maior probabilidade de reconhecer-se capaz de contribuir e, consequentemente, possa encontrar-se mais próximo da percepção de que essas áreas do conhecimento não lhe são inalcançáveis. Os problemas e as questões propostas envolvem textos midiáticos nos quais conceitos científicos são tratados incorretamente ou de forma sensacionalista, no intuito de se contribuir para que os alunos ampliem sua percepção da necessidade de se questionar a confiabilidade das fontes de informação.

Palavras-chave: Ensino de matemática. Ensino de ciências. Interdisciplinaridade. Sequência didática.

\section{ABSTRACT}

Some beneficial aspects are discussed in constructing a dialogue between the reality that exceeds the school wall and the scientific knowledge that it promotes, including, for this, the practice of interdisciplinarity as most complete representation of the world. Based on this discussion and the questioning of the idea that mathematics and natural sciences as inaccessible to a large part of the public, we propose the example of a didactic sequence in which the participation of student teams is invited to solve problems and to answer interdisciplinary questions involving astronomy and mathematics, in order to explore multiple skills, each student is more likely to recognize himself capable of contributing and, consequently, may be closer to the perception that these areas of knowledge do not are unreachable for him. The problems and the proposed questions involve mediatic texts in which scientific concepts are treated incorrectly or sensationalistically, in order to help students to increase their perception of the need to question the reliability of information sources.

Keywords: Mathematics teaching. Science teaching. Interdisciplinarity. Didactic sequence. 


\section{Introdução}

ttie (2013) apresenta uma reflexão que consideramos interessante para o ensino de matemática e, com analogias diretas, pensamos poder ser aplicado a outras disciplinas. O autor aponta existirem relações de poder e determinismo ligados ao saber matemático. O determinismo representa certa impressão que o senso comum carrega de que algumas pessoas são naturalmente capazes de aprender matemática enquanto outras não são. É relativamente comum vermos esse tipo de naturalização em frases que até mesmo sugerem algum tipo de hereditariedade: "Meu filho não é bom em ciências exatas, puxou a mim - eu também não era".

Paralelamente a isso, o prestígio das áreas ditas "exatas" pode fazer com que sejam associadas a um patamar tão elevado que somente pessoas com inteligência excepcional podem alcançar.

A charge da Figura 1, embora elaborada na década de 1980, parece representar bem essa dimensão axiológica:

Figura 1. llustração do prestígio das áreas de Exatas

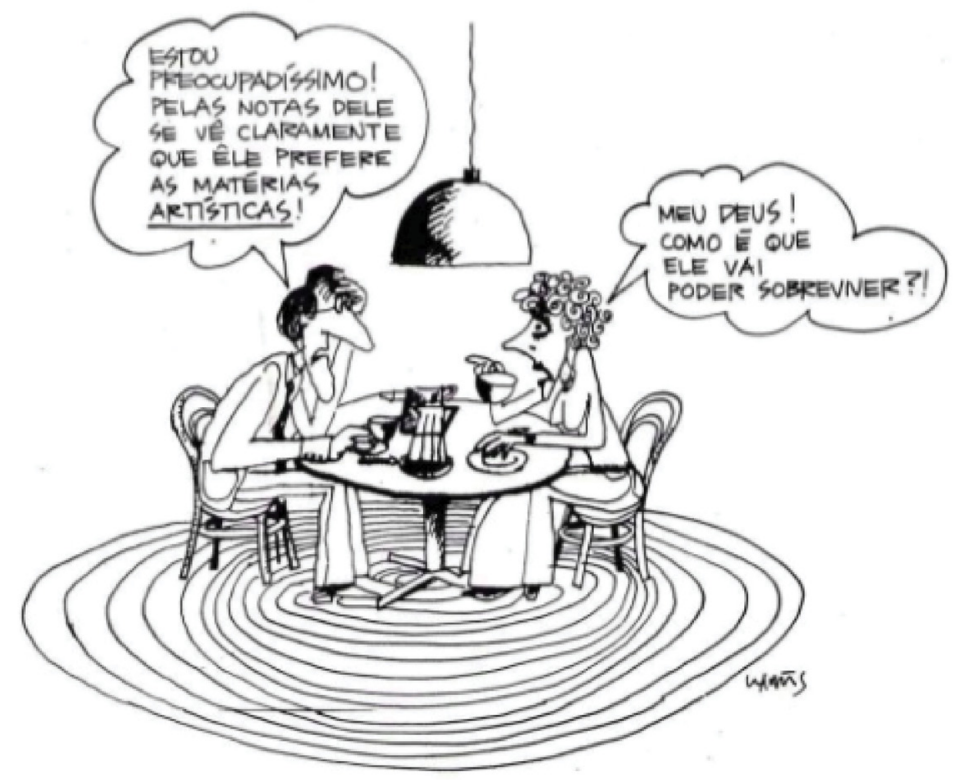

Fonte: HARPER et al., 1987. 
Isso redunda na impressão de que matemática e ciências naturais são acessíveis apenas a gênios, de modo que alguém que tem uma dificuldade inicial para aprender já pode sentir-se induzido a desistir, uma vez que não há como aprender aos poucos ou em parte: ou se é bom ou se é ruim nessas áreas; não há tons intermediários. Nas palavras do próprio pesquisador:

Saber matemática parece ser um domínio em que, no sentimento da maioria das pessoas, não existem meios termos. Ou a pessoa sabe matemática, ou não sabe, é o que se acredita e se propaga (ATTIE, 2013, p. 2).

É possível acrescentarmos a hipótese que a apresentação dos temas a serem estudados de modo desconectado do mundo e segmentado em disciplinas que não se comunicam contribui para intensificar o distanciamento que os estudantes sentem em relação a essas áreas do conhecimento.

Neste trabalho, partiremos das considerações de Attie (2013) e da hipótese que acabamos de levantar para propor uma sequência didática na qual possamos convergir as discussões teóricas que aqui serão apresentadas, fazendo dela uma proposta ilustrativa que tanto possa servir como elemento para outras discussões teóricas como para ser adaptada e aplicada.

\section{Articulações no ensino de matemática: algumas considerações sobre cotidiano e interdisciplinaridade}

Duas características que poderíamos elencar como de relevância para a formulação de uma sequência didática seriam:

1. Articulação com outras disciplinas. Visto que o mundo não é setorizado em disciplinas separadas, não parece que a fragmentação do conhecimento fornece uma perspectiva suficiente ou completa a partir da qual os estudantes podem conhecer o mundo e dialogar com ele.

2. Articulação com a realidade além da sala de aula, com o cotidiano e com problemas e questões que ou estão presentes no mundo que cerca os estudantes ou permitem que eles ampliem sua visão desse mundo.

No sentido da primeira articulação mencionada, a Base Nacional Comum Curricular (BNCC) propõe um ensino de matemática interdisciplinar e dentro de uma perspectiva histórico-cultural quando a reconhece como conhecimento humano e que humaniza: 
[...] a Matemática é uma ciência humana, fruto das necessidades e preocupações de diferentes culturas, em diferentes momentos históricos, e é uma ciência viva, que contribui para solucionar problemas científicos e tecnológicos e para alicerçar descobertas e construções, inclusive com impactos no mundo do trabalho (BNCC, 2018, p. 267).

O pensar a interdisciplinaridade envolvendo a matemática talvez represente uma transformação axiológica, isto é, da forma como se concebe o valor desta área do conhecimento: possivelmente superando o ideal de simples status para que se possa pensar formas de favorecer a elaboração de uma valorização com as demais áreas em lugar de uma valorização em detrimento das demais áreas do conhecimento.

Tal mudança de postura (de valorização em detrimento para valorização com as demais áreas) não precisa, segundo entendemos, ser entendida como uma diminuição do papel ou da importância atribuída à matemática. É possível que se dê mesmo o oposto: justamente ao se articular com outras áreas e com elementos da realidade concreta dos estudantes, talvez possa ocorrer de cada disciplina mostrar com mais facilidade o quão importante é e tem sido na história da humanidade, despertando mais interesse dos alunos e, eventualmente, até atraindo mais jovens para profissões de pesquisa científica e/ou docência nessas áreas.

Se falamos em articular os temas de matemática com o cotidiano e com outras disciplinas, pode caber esclarecer alguns pontos a respeito daquilo a que não estamos nos referindo ou pontuar algumas defesas que não pretendemos fazer quando dizemos isso. Por exemplo, quando falamos em cotidiano, não é nosso intuito defender que todo ensino deve ser voltado para utilidades concretas ou cotidianas, mas simplesmente que esse elemento também é relevante.

Em outras palavras, não é nossa pretensão que o ensino de matemática (nem o de outras áreas) seja desprovido de discussões abstratas e/ou sem relação direta com o cotidiano, uma vez que discussões dessa monta constituem o bojo de grande parte do arcabouço filosófico e cultural de que a humanidade dispõe e parece-nos que, de certa forma, cabe à escola justamente colocar os educandos em contato com esse tesouro cultural. Para se ter um exemplo, não entendemos que a importância de se conhecer clássicos da literatura, de se ouvir uma sinfonia ou de se prestigiar uma pintura ou escultura está circunscrita à sua "utilidade" - da mesma forma, não vemos por que a utilidade haveria de ser o parâmetro único em decisões pedagógicas para o ensino de matemática. Entretanto, já que a matemática tem relevância e aplicações notáveis em questões do dia a dia, parece bastante sensato sugerir que essas relações sejam exploradas quando possível.

Além disso, parece-nos que favorecer a relação entre o conhecimento escolar e a realidade "além-muros" pode ser uma forma de se reconhecer que há alguma legitimidade no questionamento comumente levantado por discentes 
- "por que tenho que aprender isso?" - e, ainda mais, talvez seja um caminho para fornecer respostas, justamente de um tipo que não requer o apelo à autoridade do "porque o vestibular exige", "porque vai cair na prova" ou "porque está no programa curricular".

Além do tópico da relação com o "mundo exterior", falamos também em interdisciplinaridade. E parece-nos igualmente importante fazer um esclarecimento sobre este ponto: interdisciplinaridade, no nosso entender, requer uma participação efetiva de diferentes disciplinas na solução de um problema, não constituindo interdisciplinaridade a situação em que uma ou mais áreas são simplesmente mencionadas sem que, contudo, seus conhecimentos participem efetivamente da discussão pretendida. Por exemplo, não entendemos que há interdisciplinaridade entre matemática e literatura em uma questão que diz "Um livro de Machado de Assis tem capa retangular cujas dimensões são 10 $\mathrm{cm}$ e $20 \mathrm{~cm}$. Calcule a área dessa capa". A referência ao livro e ao escritor existe, mas não tem qualquer relevância na resolução do problema proposto: calcular uma área - para esse problema, nenhum conhecimento de literatura é necessário, bastando saber geometria. Esse esclarecimento nos pareceu oportuno já que entendemos que há um número sensível de questões - em livros, vestibulares e outras provas - que seguem estrutura semelhante à essa e talvez passem a impressão de serem interdisciplinares.

Pretendemos que a sequência didática que será proposta leve em conta as considerações que acabam de ser apresentadas. Para tanto, propomos interação entre matemática e astronomia na discussão de matérias jornalísticas onde informações científicas são distorcidas. Uma vez que notícias e divulgações científicas fazem parte do cotidiano, podem representar um ponto de partida para discussões em sala de aula. Além disso, incentivar os estudantes a questionar fontes de informações pode ser interpretado como um papel importante da formação dos sujeitos.

Para que a sequência construída procure minimizar a reprodução dos efeitos, já mencionados, de distanciamento e restrição da matemática e da ciência astronômica como inalcançáveis, nossa proposta buscará não manter a organização típica, na qual o professor já inicia expondo os conteúdos. Adotaremos a estratégia na qual o professor propõe um problema e a turma é levada a pensar e discutir soluções. Supomos que essa estratégia, não muito desconhecida, pode ter a vantagem de, por permitir um trabalho em que as respostas são discutidas em várias etapas, nas quais o intuito não é alcançar rapidamente a equiparação com um gabarito, não classifica com a mesma intensidade os estudantes em "bons" e "ruins" no assunto. Reconhecemos que tal proposta não é $a$ resposta, nem esperamos que seja, para os problemas apontados, mas - uma vez que múltiplas tarefas se fazem necessárias (desenhar, avaliar os números, fazer alguns cálculos, juntas informações astronômicas que podem ter sido obtidas em livros, filmes de ficção etc.) - é maior a probabilidade de que cada estudante, trabalhando em equipe, tenha algo a contribuir na realização da atividade, diferentemente do que ocorreria em uma atividade individual e que exigisse 
apenas a realização de cálculos, por exemplo. Assim, cremos que aumentam consideravelmente as chances de cada estudante encontrar algo para contribuir e, assim, perceber que pode ser "bom" em ciências e matemática e que tais áreas não lhe estão vetadas.

\section{Elaboração da sequência didática}

Sugere-se que a aplicação da sequência didática - planejada para o ensino fundamental ( $6^{\circ}$ ao $9^{\circ}$ ano $)$ - está estruturada em aproximadamente quatro aulas - seja iniciada com propondo que os estudantes discutam a seguinte pergunta desencadeadora de futuras ações: Como é o Universo?

Uma pergunta desencadeadora é assim denominada quando coloca o sujeito em atividade de estudo (MOURA, 2010): o estudante, envolvido no processo de estudo (MOURA, 2010), permite ao professor realizar a avaliação do desenvolvimento psicológico do sujeito, assim o professor pode ter alcançado o objetivo de sua atividade que seria planejar e propor uma situação didática que gere motivo no sujeito de aprender.

Na teoria histórico-cultural (VYGOTSKY, 2001; 2004), temos a definição de zona de desenvolvimento proximal (ou potencial): nela o sujeito carrega informações que lhe conferem autonomia e potencial para avançar e construir conceitos quando confrontado com nova informação externa, o que pode corresponder a aprender com o mais capaz. Por isso, a intenção, ao fazermos a pergunta “Como é o Universo?", não tem sentido se for respondida por um sujeito isolado (pois estaria desprovido da possibilidade de discutir suas proposições), mas cumpre seu propósito se for pensada individualmente e posteriormente compartilhada, pois na socialização o estudante organiza seu pensamento ao expor sua ideia, tendo ainda a oportunidade de ouvir as dos colegas.

Em um segundo momento, propõe-se uma roda de conversa, na qual os estudantes compartilham suas impressões e o professor pode registrar as palavras mencionadas pelos estudantes (supõe-se a eventual ocorrência de palavras como: planeta, satélite, estrela, sol, universo, galáxia, buraco negro), a serem exploradas na etapa subsequente da aula, que consiste, na sequência desta proposta, em organizar, na forma de painel, as palavras mencionadas na dinâmica com os estudantes. Nessa etapa, os estudantes divididos em dois grupos, em posse das palavras e do painel (suporemos que confeccionado de material que permita a mobilidade das fichas onde estão escritas as palavras, como feltro ou elemento magnético), são convidados a discutir e propor respostas às seguintes questões:

1. Como o Universo é estruturado?

2. Como as estruturas do Universo se agrupam?

3. Quais estruturas menores são contidas por outras maiores?

Educação Por Escrito, Porto Alegre, v. 10, n. 1, jan.-jun. 2019: e32716 
Aqui a escolha das palavras 'contém' e 'contido' é intencional, a fim de fomentar a internalização do conceito de organização em conjuntos, uma vez que os conceitos de conter e estar contido em desempenham papel de relevância teoria dos conjuntos.

Assim, para favorecer a construção intuitiva desses conceitos, sugere-se que os estudantes sejam convidados a organizar as estruturas do universo em um formato conhecido como diagrama de Euler, muito utilizado na já citada teoria de conjuntos: esses diagramas seriam montados na forma de figuras (como ovais) umas internas às outras, cada uma representando um conjunto de astros, para representar a hierarquia de composição, do tipo, estrela, planetas, satélites e asteroides formam sistemas planetários; estrelas e nebulosas formam galáxias, as quais compõem grupos, aglomerados e superaglomerados de galáxias.

A etapa seguinte consistiria na socialização e discussão dos resultados de cada grupo, propondo-se questões como: Quais diferenças existem entre os painéis montados por cada grupo e como podemos justificar essas diferenças? Quais detalhes cada grupo procurou ressaltar? Quais palavras diferentes cada grupo acrescentou? O que eu sei sobre isso e o que posso acrescentar? É possível mudar alguma coisa na organização montada por meu grupo?

A intenção não é que os estudantes cheguem, nesse momento, à formulação de painéis concordantes com o conhecimento astronômico vigente. Sugere-se que os painéis fiquem expostos e sujeitos a constante revisão pelo grupo, conforme forem avançando em estudos sobre o tema - tendo contato com as notícias e demais pesquisas que realizarem movidos por curiosidade.

$\mathrm{Na}$ aula de revisitação à organização por eles construída vamos acrescentar uma segunda questão "O quão grande é o Universo?". O professor pode escolher assistir a um vídeo que compara o tamanho de objetos do Universo e instruir os alunos a registrar as distâncias mencionadas para posteriormente discutirem as questões referentes à leitura dos números, notação científica, explicar como são definidas essas distâncias e dimensões, quais unidades de medida são usadas em escalas astronômicas.

Neste ponto pode ser cabível explicar para a turma o princípio cosmológico, segundo o qual o Universo em grande escala é homogêneo e isotrópico. A palavra homogêneo pode ser mais fácil de explicar, pode estar no cotidiano de algum estudante que compartilhando no grupo pode se tornar comum, pois a palavra homogêneo aparece em receitas "misture os ingredientes até conseguir uma massa homogênea".

A ideia de o Universo ser isotrópico pode ser explicada com o seguinte exemplo: um observador no Japão ajusta seu telescópio de grande escala e o que vê tem as mesmas características do que veria se estivesse aqui no Brasil, ou seja, não importa a direção que se observa o Universo, ele é igual.

Quando os estudantes tiverem discutido essas escalas, pode ser conveniente provocar as seguintes questões (se não ocorrerem naturalmente): Se somos tão pequenos e estamos tão próximos uns dos outros, em comparação com 
um Universo tão grande, como podemos nos colocar uns contra os outros? Se somos pequenos em estatura, mas ainda assim podemos estudar algo da grandiosidade do Universo, isso não nos torna de algum modo grandes? Podem-se explorar quadrinhos que trazem provocações dessa natureza, como os exemplos das Figuras 2 e 3 .

Figura 2. Tirinha de Calvin e Haroldo por Bill Watterson

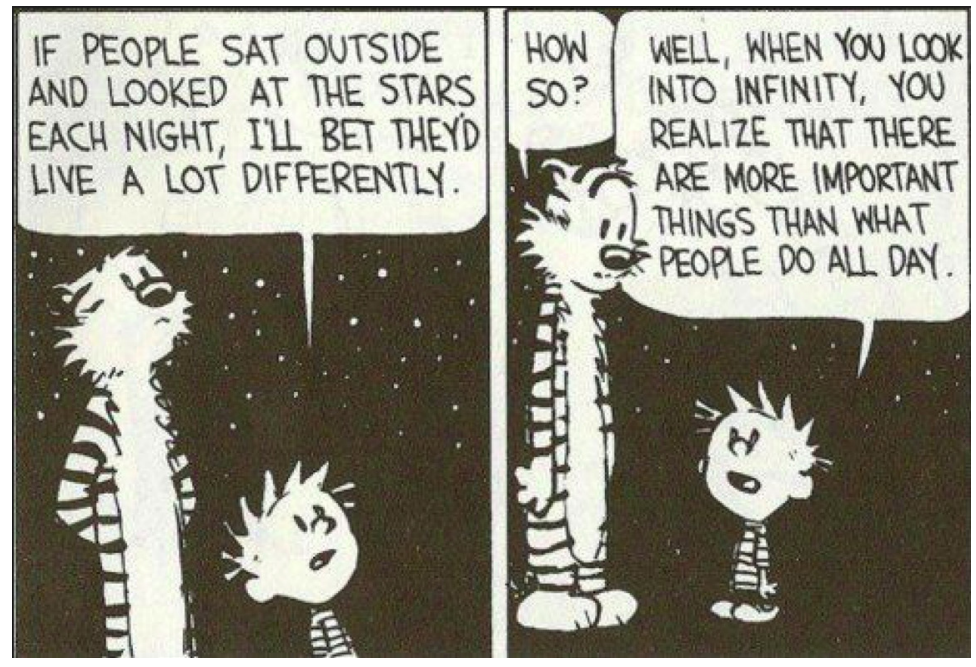

Figura 3. Tirinha The Awkard Yeti

Fonte: https://www.gocomics.com/calvinandhobbes/1992/06/30 ${ }^{1}$

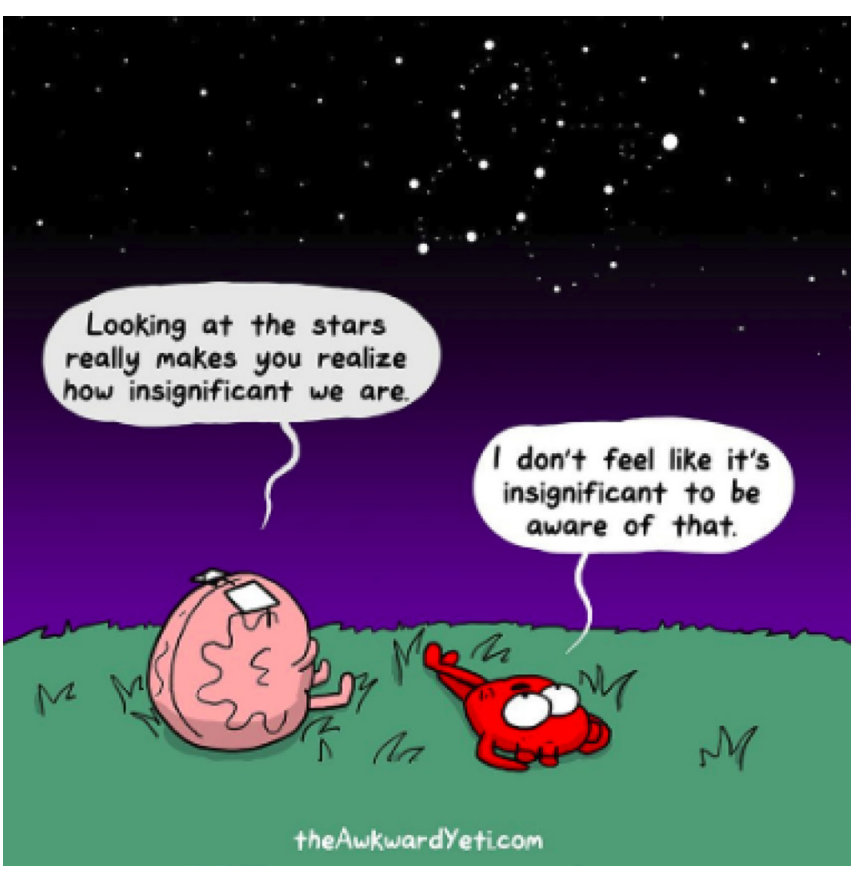

Fonte: http://theawkwardyeti.com²

\footnotetext{
1 "Se as pessoas saíssem e olhassem as estrelas toda noite, aposto que viveriam de modo muito diferente. / Como assim? / Bem, quanto você olha para o infinito, você percebe que há coisas mais importantes do que aquilo que as pessoas fazem todos os dias" (tradução nossa)

2 "Olhar para as estrelas nos faz perceber o quanto somos insignificantes. / Mas não é nada insignificante ter consciência disso" (tradução nossa)
} 
Discutir o lugar do ser humano no Universo pode ser desejável na educação escolar, inclusive porque isso promove, em parte, o que reza a Constituição Federal, em seu artigo 205, quando diz que a Educação deve ser promovida e incentivada "visando ao pleno desenvolvimento da pessoa" (BRASIL, 1988).

É possível encontrar, na área de astronomia, notícias sensacionalistas e/ou que carregam eventuais erros conceituais. Em alguns casos, números muito grandes são apresentados sem que um contexto mais claro permita que o leitor os interprete; em outros, esse sensacionalismo assume um tom que poderíamos talvez classificar como apocalíptico, como exemplificado na frase abaixo, onde é narrada a detecção da explosão de uma estrela.

Incluir astronomia na aula de matemática se apresenta como uma possibilidade adicional para o estudo desta temática nas escolas regulares, visto que os livros didáticos contemplam temas básicos do sistema solar para o ensino fundamental e nem sempre contemplam temas atuais, segundo LIMA Jr. et al. (2017). Ainda é uma oportunidade para rever e consolidar as aprendizagens, pois. cita erros conceituais mais comuns que estão presentes no currículo escolar.

"Uma monstruosa explosão rachou uma estrela talvez 150 vezes mais robusta que nosso Sol, numa galáxia relativamente próxima, ...” (DUNHAM, 2007).

Informar que a explosão ocorreu em uma galáxia próxima pode imprimir certa sensação de medo em um leitor que desconhece escalas astronômicas e o alcance do material ejetado durante um colapso de tal natureza.

As notícias a serem analisadas no decorrer dos encontros com o grupo podem ser trazidas pelos próprios estudantes e outras podem ser propostas pelo professor. Os estudantes fariam a leitura em grupo identificando o equívoco em cada notícia com base nos conhecimentos e na habilidade de pesquisa e questionamentos.

Como exemplo do que sugerimos para esta etapa apresentam-se duas notícias:

1a notícia: Terra tem "duas Luas" há 100 anos e a Nasa só descobriu isso neste ano3.

O corpo da notícia descreve que um objeto, com diâmetro entre 36 e 91 metros, que está descrevendo uma órbita aparentemente em torno da Terra, o que o faz ser comparável a um segundo satélite de nosso planeta. Além das imprecisões astronômicas da matéria, é possível explorar os dados fornecidos sobre o asteroide 2016HO3 e sugerir que os estudantes o comparem com as dimensões de outros corpos que orbitam a Terra: satélites artificiais e estações espaciais, por exemplo. É possível encontrar, além disso, para este e outros corpos, animações que ilustram como seus movimentos em torno do Sol, sob influência da Terra, apenas aparentemente formam órbitas fechadas próximas de nosso planeta - de maneira que não constituem verdadeiros satélites nossos.

3 Disponível em: https://br.noticias.yahoo.com/terra-tem-duas-luas-h\%C3\%A1-100-anos-e-a-nasa-s\%C3\%B3-171744262.html. Acesso em: 10 dez. 2018. 


\section{2aㅡ Notícia de 2004: Satélite europeu prova que Muralha da China é visível do espaço}

Com essa notícia podemos discutir a necessidade de definição de espaço. No decorrer da notícia encontramos o dado define o 'espaço' mencionado no título: "Na órbita terrestre, entre 160 e 320 quilómetros, a Grande Muralha da China é mesmo visível a olho nu". Para discutir essas informações com os estudantes, antes de buscar informações que afirmam se a notícia é ou não correta, algumas questões problematizadoras iniciais podem ser propostas. Uma primeira questão pode ser: "o que podemos entender como espaço?", já que é importante distinguir o espaço logo após deixar as camadas mais densas da atmosfera do espaço na altura da órbita da Lua ou, ainda, além disso. Outra questão envolve reconhecer a diferença entre duas dimensões na Grande Muralha: o comprimento e a largura. Ainda que a muralha seja comprida, sua largura é suficiente para que seja visível do espaço? E a sua cor, permitiria contraste suficiente para que se pudesse distinguir do ambiente visualizado a tal distância?

Para finalizar a sequência, sugere-se que os alunos avaliem o próprio aprendizado, buscando fazer o levantamento do que aprenderam no decorrer dessas aulas, que conceitos desenvolveram, que novas concepções foram adquiridas. Pode mostrar-se apropriado fazer isso em dois formatos: um coletivo, em forma de dinâmica do tipo "roda de conversa", para favorecer a troca de experiências, e outro individual, por escrito, onde cada estudante tem a oportunidade de colocar aquilo (inclusive dúvidas) que eventualmente não gostaria de expor diante dos colegas.

\section{Considerações finais}

Divulgações científicas e notícias que veiculam informações com temas científicos são bastante acessíveis. Atualmente extrapolam veículos que até uma década atrás eram os principais meios de informação (nomeadamente a TV, o rádio e as mídias impressas), estando presentes em smartphones, tablets e outros meios de conexão que literalmente cabem na palma da mão. O fluxo de informações hoje é inédito e pode residir aí um papel da educação escolar: formar cidadãos capazes de lidar com essas informações, dentre outras coisas, reconhecendo conceitos científicos, cotejando fontes para verificar a exatidão do que está sendo dito e questionando a validade de diferentes fontes.

A imagem de matemática e ciências naturais como conhecimentos inacessíveis ou restritos a "escolhidos" pode restringir o acesso, mesmo de pessoas que passaram por todos os níveis da Educação Básica, a informações de relevância. Entendendo-se que o conhecimento está disponível e, até certo ponto, é acessível e reconhecendo critérios pelos quais se pode distinguir uma fonte confiável de uma duvidosa, um cidadão pode saber como e onde

4 Disponível em: https://www.publico.pt/2004/05/11/ciencia/noticia/satelite-europeu-prova-que-muralha-da-china-e-visivel-doespaco-1193488. Acesso em: 9 dez. 2018. 
obter informações úteis, por exemplo, para sua saúde, estaria, inclusive, provavelmente menos propenso a ser vítima de certos golpes e teria possivelmente maior facilidade para pesquisar leis, normas e obter garantia de seus deveres e direitos civis.

Não pretendemos que a sequência didática aqui proposta seja capaz de formar cidadãos assim, mas esperamos que ela adicione um elemento a contribuir para as discussões sobre esse tipo de formação.

\section{Referências}

ATTIE, João Paulo. Relações de poder no processo de ensino e aprendizagem de matemática. Tese (Doutorado em Educação) Faculdade de Educação, Universidade de São Paulo, São Paulo, 2013. https://doi.org/10.17143/ciaed/xxiilciaed.2017.00382

BRASIL, Ministério da Educação. Base Nacional Comum Curricular. Versão final, maio de 2018. Brasília, DF: MEC, 2018. Disponível em: http://basenacionalcomum.mec.gov.br/wp-content/uploads/2018/06/BNCC_EI_EF_110518_versaofinal_site.pdf. Acesso em: 9 dez. 2018.

DUNHAM, W. Estrela explode e cria a maior Supernova já vista. G1: O portal de notícias da Globo, [Rio de Janeiro], 7 maio 2007. Disponível em: http://g1.globo.com/Noticias/Mundo/0,,AA1534118-5602,00-ESTRELA+EXPLODE+E+CRIA+A+MAIOR+SUPE RNOVA+JA+VISTA.html. Acesso em: 9 dez. 2018.

HARPER, Babette; CECCON, Claudius; OLIVEIRA, Miguel Darcy de; OLIVEIRA, Rosiska Darcy de. Cuidado, Escola! São Paulo: Brasiliense, 1987.

LIMA JR., J. G. S.; ANDRADE, J. E.; DANTAS, J. M.; GOMES, L. M. Uma reflexão sobre o ensino de Astronomia na perspectiva da Base Nacional Comum Curricular. Scientia Plena, [s. l.], v. 13, n. 1, 2017. https://doi.org/10.14808/10.14808/sci. plena.2017.012707

MOURA, M.O (org.). A atividade pedagógica na teoria histórico cultural. Brasília, DF: Liber Livro, 2010.

VIGOTSKI, L. S. A construção do pensamento e da linguagem. Trad. Paulo Bezerra.

São Paulo: Martins Fontes, 2001.

VIGOTSKI, L. S. Teoria e método em Psicologia. Trad. Claudia Berliner. 3. ed. São Paulo: Martins Fontes, 2004.

Recebido em: 10/12/2018.

Aprovado em: 6/8/2019.

Publicado em: 31/12/2019. 


\section{Endereço para correspondência:}

Amanda Cristina Tedesco Piovezan

Rua Prof. Vicente Peixoto, 50 - Vila Indiana

05590-000, São Paulo, SP, Brasil

\section{Autores:}

Amanda Cristina Tedesco Piovezan

Possui graduação em Matemática pela Universidade Ibirapuera (2006). Cursando o Mestrado Profissional em Ensino de Astronomia no IAG-USP desde 2017.

Atua como professora do ensino fundamental II e médio da Prefeitura Municipal de São Paulo na Unidade EMEF Des. Amorim Lima desde 2017.

Orcid: http://orcid.org/0000-0002-2699-5355

E-mail: amanda.piovezan@usp.br

LEANDro Daros GAMA

Doutorado em Ensino de Ciências (Modalidades Física, Química e Biologia) pela Universidade de São Paulo, Brasil (2016).

Professor E.B.T.T. do Instituto Federal de Educação, Ciência e Tecnologia de São Paulo, Brasil.

Orcid: http://orcid.org/0000-0001-5676-5051

E-mail: gama@if.usp.br

Endereco: Rua Pedro Vicente, 625 - Canindé

01109-010, São Paulo, SP, Brasil 